\title{
Effects of KIF2A on the prognosis of nasopharyngeal carcinoma and nasopharyngeal carcinoma cells
}

\author{
QIUCHAN ZHANG, DONGLING LU, WENLIN LIU, SHIJIE YE, \\ HUANPING GUO, TIANYI LIAO and CUIFANG CHEN \\ Department of Otorhinolaryngology-Head and Neck Surgery, The Sixth Affiliated Hospital of \\ Guangzhou Medical University, Qingyuan People's Hospital, Qingyuan, Guangdong 511518, P.R. China
}

Received January 3, 2019; Accepted June 13, 2019

DOI: $10.3892 / \mathrm{ol} .2019 .10597$

\begin{abstract}
Nasopharyngeal carcinoma (NPC) is a common tumor in south China. Kinesin family member 2A (KIF2A) belongs to the kinesin-13 family and is associated with the growth and invasion of a number of different types of human cancer, including ovarian, breast and prostate cancer. The aim of the present study was to evaluate the expression of KIF2A in NPC and explore the relationship between KIF2A and the basic characteristics of $5-8 \mathrm{~F}$ cells. Immunohistochemistry was performed on tissues from 97 patients with NPC to assess KIF2A protein expression. KIF2A was knocked down by a specific short interfering (si)RNA in $5-8 \mathrm{~F}$ cell lines. Cell proliferation, apoptosis and cycle were analyzed by MTT assay and flow cytometry. The invasive ability and angiogenesis were evaluated by Matrigel assay and reverse transcription-quantitative PCR. The level of KIF2A was associated with the growth and migration of primary tumor, nodal status and tumor stage. The viability of KIF2A-knockdown cells was decreased compared with that of the control cells. The number of apoptotic cells, as well as the percentage of cells in the G0/G1 phase, was higher in the KIF2A siRNA group compared with the control group. The invasive and angiogenetic ability of 5-8F cells in the KIF2A siRNA group was decreased compared with the control group. In conclusion, the expression of KIF2A correlated with the poor clinicopathological features in NPC. Therefore, KIF2A may serve an important role in the progression of NPC and proliferation of 5-8F cells, which might present a potential therapeutic target for patients with NPC.
\end{abstract}

Correspondence to: Professor Cuifang Chen, Department of Otorhinolaryngology-Head and Neck Surgery, The Sixth Affiliated Hospital of Guangzhou Medical University, Qingyuan People's Hospital, B24 Yinquan Road South, Qingyuan, Guangdong 511518, P.R. China

E-mail: cuifangchen123@163.com

Key words: kinesin family member 2A, nasopharyngeal carcinoma, clinicopathological features, $5-8 \mathrm{~F}$ cells

\section{Introduction}

Nasopharyngeal carcinoma (NPC), which is a malignant tumor, is the most prevalent head and neck cancer in south China (1-3). The pathogenesis of NPC is complicated, including the Epstein-Barr virus (EBV) infection, carcinogen hazards and individual susceptibility $(1,4)$. In clinic, NPC exhibits low differentiation and high rates of metastasis compared with other types of cancers (5-7). Although chemotherapy and radiotherapy are used, the treatment efficacy for NPC is still unsatisfactory due to the local recurrence and distant metastasis $(5,8)$. Therefore, it is important to understand the molecular mechanisms of NPC.

The kinesin superfamily proteins (KIFs) are a conserved class of microtubule-dependent motor proteins that serve the role of oncogenes in cancer cells $(9,10)$. Microtubules (MTs) are the important components of cytoskeleton are vital for mitotic activity of tumor and for invading tissues (9). Kinesin family member 2A (KIF2A), which is a member of the kinesin-13 family, is associated with the process of mitosis and mitotic spindle assembly in cancer cells $(11,12)$. KIF2A is able to inhibit the process of microtubule polymerization and is vital for the tumor growth and invasion (11). Recent studies have demonstrated that KIF2A is involved in carcinogenesis and prognosis in different types of human cancer, such as prostate, breast and ovarian cancer (13-15). However, the role of KIF2A in human NPC is still unknown.

The aim of the present study was to investigate the function of KIF2A in the prognosis of nasopharyngeal carcinoma and nasopharyngeal carcinoma cells. The expression of KIF2A was examined in 97 human NPC tumor samples; the prognostic value of KIF2A for patients NPC was evaluated, and the biological functions of KIF2A in the 5-8F NPC cell line were analyzed.

\section{Materials and methods}

Patient specimens. A total of 97 patients (47 male, 50 female; age range, 25-78 years; median age, 44 years) diagnosed with NPC by biopsy between January 2017 and June 2018 at the Sixth Affiliated Hospital of Guangzhou Medical University (Guangdong, China) were included in the present study. All specimens had confirmed pathological diagnosis and were 
classified according to the World Health Organization (WHO) Tumor-Node-Metastasis staging system $(16,17)$. The patients with a history of radiotherapy or chemotherapy were excluded. Sample collection protocols were approved by the Ethics Committee of the Sixth Affiliated Hospital of Guangzhou Medical University (approval no. ERC-2016-33). Written informed consent was obtained from all patients.

Immunohistochemistry. Immunohistochemical staining assays were performed on NPC tissue sections using the EnVision Detection system according to the manufacturer's protocol. Briefly, the tissues were fixed in $4 \%$ paraformaldehyde for $24 \mathrm{~h}$ at $4^{\circ} \mathrm{C}$ and embedded in paraffin, and then six consecutive sections $(4 \mu \mathrm{m})$ were obtained from each tissue. The sections were incubated with a KIF2A primary antibody (1:500; catalog no. PA1-640; Thermo Fisher Scientific, Inc.) overnight at $4^{\circ} \mathrm{C}$. The slides were treated with horseradish peroxidase-conjugated secondary antibodies (1:1,000; catalog no. GP016029; Gene Tech Co, Ltd.). The negative controls included the sections incubated without primary antibodies. The sections were evaluated and scored by three independent pathologists according the percentage of positive-stained cells $(0,0 \% ; 1,1-10 \% ; 2,11-60 \% ; 3,61-75 \%$; and $4,76-100 \%)$. The average staining intensity was calculated, and an average score $<3$ was considered as weak KIF2A protein expression, and an average score $\geq 3$ was considered strong.

Cell culture and RNA interference. The human NPC cell line $5-8 \mathrm{~F}$ was purchased from the Cancer Institute, Southern Medical University (Guangdong, China). Cells were maintained in RPMI-1640 medium (Invitrogen; Thermo Fisher Scientific, Inc.) supplemented with $10 \%$ fetal bovine serum (FBS; Thermo Fisher Scientific, Inc.), $100 \mathrm{U} / \mathrm{ml}$ penicillin and $100 \mu \mathrm{g} / \mathrm{ml}$ streptomycin in a humidified atmosphere with $5 \% \mathrm{CO}_{2}$ at $37^{\circ} \mathrm{C}$. For RNA interference, 5-8F cells were transfected with $50 \mathrm{nM}$ KIF2A small-interfering (si)RNA (5'-GGCAAAGAGAUUGACCUGG-3'; Invitrogen; Thermo Fisher Scientific, Inc.) with Lipofectamine ${ }^{\circledR} 2000$ (Invitrogen; Thermo Fisher Scientific, Inc.) according to the manufacturer's protocol. Scrambled siRNA (5'-AUCAGC AUACCUCA-3') and mock treatment (using Lipofectamine) were used as controls.

Western blotting. Cells were collected and treated with RIPA buffer (Beyotime Institute of Biotechnology) on ice and the extracted protein was quantified by a bicinchoninic acid kit (Beyotime Institute of Biotechnology). A total of $30 \mu \mathrm{g}$ protein sample was separated by $10 \%$ SDS-PAGE and subsequently transferred onto a PVDF membrane (18). Following blocking with $5 \%$ BSA in TBS $+0.1 \%$ Tween- 20 for $1 \mathrm{~h}$, the membrane was incubated with antibodies against KIF2A (1:500; catalog no. PA1-640; Thermo Fisher Scientific, Inc.) or $\beta$-actin (1:1,000; catalog no. 3700; Cell Signaling Technology, Inc.) overnight at $4^{\circ} \mathrm{C}$. The membrane was subsequently incubated with horseradish peroxidase-conjugated goat anti-mouse secondary antibodies (1:1,000; catalog no. GP016029; Gene Tech Co., Ltd.) for $1 \mathrm{~h}$. The results were analyzed using the fluorescence imaging system (Bio-Rad Laboratories, Inc.). The density of the protein bands was analyzed using ImageJ software (version 1.8.0; National Institutes of Health).
Table I. Reverse transcription-quantitative PCR primer sequences.

\begin{tabular}{llc}
\hline Gene & \multicolumn{1}{c}{ Sequence $\left(5^{\prime} \rightarrow 3^{\prime}\right)$} & Size $(\mathrm{bp})$ \\
\hline KIF2A & F: AAGGCAAAGAGATTGACCTGG & 151 \\
& R: GAAGCTACAGTCCGTCGATTC & \\
Bcl-2 & F: GGTGGGGTCATGTGTGTGG & 89 \\
& R: CGGTTCAGGTACTCAGTCATCC & \\
Bax & F: CCCGAGAGGTCTTTTTCCGAG & 155 \\
& R: CCAGCCCATGATGGTTCTGAT & \\
VEGF & F: AGGGCAGAATCATCACGAAGT & 75 \\
& R: AGGGTCTCGATTGGATGGCA & \\
GAPDH & F: CTGGGCTACACTGAGCACC & 101 \\
& R: AAGTGGTCGTTGAGGGCAATG & \\
\hline
\end{tabular}

KIF2A, kinesin family member 2a; VEGF, vascular endothelial growth factor.

Reverse transcription-quantitative PCR. Total RNA was extracted from cells using TRIzol ${ }^{\circledR}$ reagent (Invitrogen; Thermo Fisher Scientific, Inc.). Following quantitation, $5 \mu \mathrm{g}$ total RNA was reverse-transcribed into cDNA using a PrimeScript $^{\mathrm{TM}}$ RT reagent kit (Takara Bio, Inc.) according to manufacturer's protocol. The mRNA expression levels were detected with the $2^{-\Delta \Delta \mathrm{Cq}}$ method using SYBR Green kit (Takara Bio, Inc.) with specific primers (19). The thermocycling conditions were as follows: 45 cycles of $95^{\circ} \mathrm{C}$ for $5 \mathrm{~min}, 95^{\circ} \mathrm{C}$ for $30 \mathrm{sec}, 57^{\circ} \mathrm{C}$ for $30 \mathrm{sec}$ and $72^{\circ} \mathrm{C}$ for $1 \mathrm{~min}$. The gene-specific primers were synthesized by Sangon Biotech Co., Ltd., and the sequences are presented in Table I.

Cell proliferation assay. Cells were seeded at the density of $1 \times 10^{3}$ cells/well in a 96-well plate and were cultured for 24 , 48 and $72 \mathrm{~h}$. Cell viability was assessed by MTT assay. MTT reagent $(5 \mathrm{mg} / \mathrm{ml}$; Amresco, LLC) was added to each well and incubated in a dark environment for $3 \mathrm{~h}$ at $37^{\circ} \mathrm{C}$ with $5 \% \mathrm{CO}_{2}$. DMSO (100 $\mu \mathrm{l} /$ well) was added into each well. Absorbance at $490 \mathrm{~nm}$ was recorded using a microplate reader (Thermo Fisher Scientific, Inc.).

Flow cytometry assay. Following cell collection $\left(1 \times 10^{6}\right)$, the cell cycle was evaluated by a Cell Cycle Analysis kit (Beyotime) in the dark for $30 \mathrm{~min}$ at $37^{\circ} \mathrm{C}$. Apoptosis was evaluated by phycoerythrin Annexin V Apoptosis Detection kit (BD Biosciences) following the manufacturer's protocol. After staining, the cells were analyzed by flow cytometry (BD Biosciences).

Cell invasion assay. The invasive ability of 5-8F cells was determined by Matrigel assay using Transwell chambers (BD Biosciences). The filters were pre-coated with $50 \mu 1$ Matrigel and incubated in a humidified incubator for polymerization. The lower compartment was filled with DMEM medium (Thermo Fisher Scientific, Inc.) supplemented with $10 \%$ FBS. Cells with $0.2 \mathrm{ml}$ serum-free DMEM were seeded in the upper compartment of the chamber $\left(2 \times 10^{5}\right.$ cells/chamber). Following incubation at $37^{\circ} \mathrm{C}$ for $24 \mathrm{~h}$, the cells on the upper 
Table II. Association between KIF2A expression and the clinicopathological features in patients.

\begin{tabular}{|c|c|c|c|c|}
\hline \multirow[b]{2}{*}{ Variable } & \multirow[b]{2}{*}{ Patients, $\mathrm{n}$} & \multicolumn{2}{|c|}{ KIF2A expression (\%) } & \multirow[b]{2}{*}{ P-value } \\
\hline & & Low, n=57 & High, $n=40$ & \\
\hline Sex & & & & 0.315 \\
\hline Male & 47 & $29(50.9)$ & $24(60.0)$ & \\
\hline Female & 50 & $28(49.1)$ & $16(40.0)$ & \\
\hline Age, years & & & & 0.827 \\
\hline$<60$ & 78 & 47 (82.5) & $30(75.0)$ & \\
\hline$\geq 60$ & 19 & $10(17.5)$ & $10(25.0)$ & \\
\hline Primary tumor & & & & $0.005^{\mathrm{a}}$ \\
\hline T1-T2 & 68 & $48(84.2)$ & $15(37.5)$ & \\
\hline T3-T4 & 29 & $9(15.8)$ & $25(62.5)$ & \\
\hline Nodal status & & & & $0.037^{\mathrm{a}}$ \\
\hline N0-N1 & 75 & $52(91.2)$ & $25(62.5)$ & \\
\hline N2-N3 & 22 & $5(8.8)$ & $15(37.5)$ & \\
\hline Stage & & & & $0.014^{\mathrm{a}}$ \\
\hline I-II & 73 & $50(87.7)$ & $15(37.5)$ & \\
\hline III-IV & 24 & $7(12.3)$ & $25(62.5)$ & \\
\hline
\end{tabular}

${ }^{\mathrm{a}} \mathrm{P}<0.05 . \mathrm{KIF} 2 \mathrm{~A}$, kinesin family member $2 \mathrm{a}$.

surface of the filter were removed using a cotton swab. Cells that traversed the filter were fixed with $10 \%$ methanol for $5 \mathrm{~min}$ at $4^{\circ} \mathrm{C}$, stained with $0.5 \%$ eosin for $30 \mathrm{~min}$ at $37^{\circ} \mathrm{C}$ and counted using a light microscope.

Statistical analysis. All experiments were performed in triplicate. Statistical analyses were performed using SPSS version 20.0 software package (IBM Corp.). One-way analysis of variance with Bonferroni correction was used for multiple comparisons. $\mathrm{P}<0.05$ was considered to indicate a statistically significant difference.

\section{Results}

Association between of KIF2A expression and clinicopathological parameters in NPC. The protein expression level of KIF2A in NPC tissue was detected by immunohistochemistry. The results demonstrated that the expression levels of KIF2A were not associated with the sex and age of patients. However, KIF2A expression levels were associated with the size, location and stage of the primary tumor, the nodal status and the tumor stage. High KIF2A expression was significantly associated with T3-T4 $(\mathrm{P}=0.005), \mathrm{N} 2-\mathrm{N} 3(\mathrm{P}=0.037)$ and stage III-IV $(\mathrm{P}=0.014)$ (Table II).

KIF2A silencing decreases $5-8 F$ cell viability. To identify the functions of KIF2A in nasopharyngeal carcinoma, siRNA knockdown of KIF2A was performed. Western blotting and RT-qPCR results confirmed that the mRNA and protein expression of KIF2A was inhibited in siRNA-transfected cells compared with the control group and the scrambled siRNA group $(\mathrm{P}<0.05$; Fig. $1 \mathrm{~A}$ and $\mathrm{B})$. The effects of KIF2A siRNA on the viability of $5-8 \mathrm{~F}$ cells were investigated by MTT assay; the results demonstrated that the viability of KIF2A-knockdown cells was decreased at 48 and $72 \mathrm{~h}$ compared with the control groups (Fig. 1C).

Effects of KIF2A silencing on the apoptosis and cell cycle of $5-8 F$ cells. To assess whether the decrease of cell proliferation induced by KIF2A siRNA was associated with apoptosis and cell cycle arrest, apoptotic rate and cell cycle of $5-8 \mathrm{~F}$ cells were examined. The results demonstrated that the number of apoptotic cells in the KIF2A siRNA group was higher compared with those in the control and scrambled siRNA groups (Fig. 2A). In the KIF2A siRNA group, the mRNA expression level of Bcl-2 was decreased, whereas the expression level of Bax was increased compared with the control groups (Fig. 2B). The cell cycle assay revealed that, compared with the control and scrambled siRNA groups, the percentage of cells in the G0/G1 phase of the cell cycle was significantly increased, whereas the percentages of cells in the $\mathrm{S}$ and G2/M phases were significantly decreased in the KIF2A siRNA group (Fig. 2C).

KIF2A knockdown inhibits the invasive ability and vascular endothelial growth factor (VEGF) expression in 5-8F cells. To evaluate the invasive ability of 5-8F cells in the KIF2A siRNA group, Matrigel cell invasion assay was performed. The results demonstrated that the invasive capacity of $5-8 \mathrm{~F}$ cells was significantly decreased in the KIF2A siRNA group compared with the control and scrambled siRNA groups $(\mathrm{P}<0.05$; Fig. 3A). In addition, the expression levels of the angiogenesis marker VEGF of 5-8F were evaluated by RT-qPCR. Compared with the control and scrambled siRNA groups, VEGF expression levels were significantly decreased in the KIF2A siRNA group $(\mathrm{P}<0.05$; Fig. 3B). 

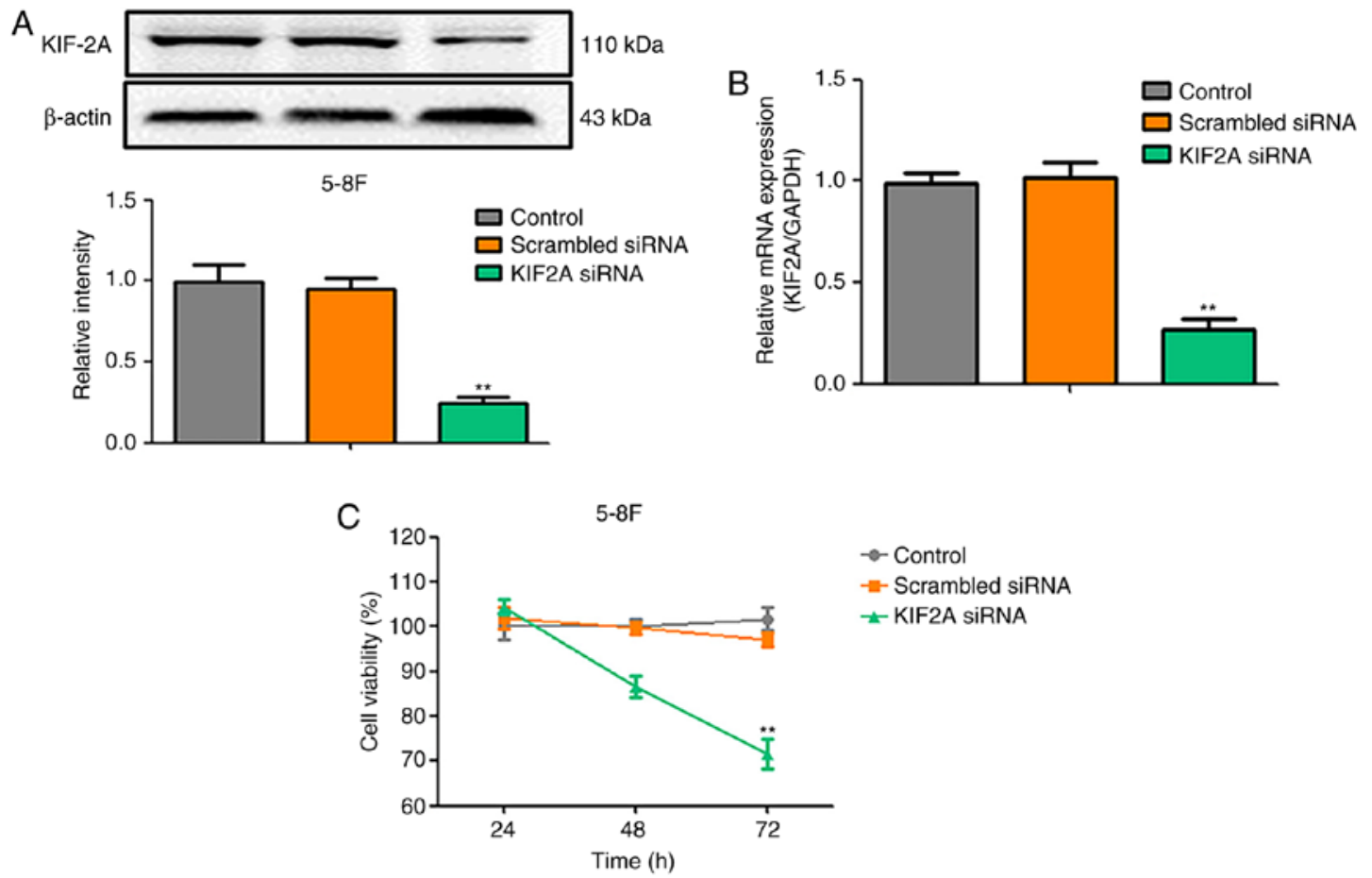

Figure 1. KIF2A siRNA decreases KIF2A expression and cell viability in 5-8F cells. (A and B) The knockdown of KIF2A was evaluated by (A) western blotting and (B) reverse transcription-quantitative PCR. (C) The effect of KIF2A knockdown on the proliferation of 5-8F was test by MTT assay. ${ }^{* *} \mathrm{P}<0.01 \mathrm{vs.}$ mock treatment control. KIF2A, kinesin family member $2 \mathrm{~A}$; siRNA, small interfering RNA.

A
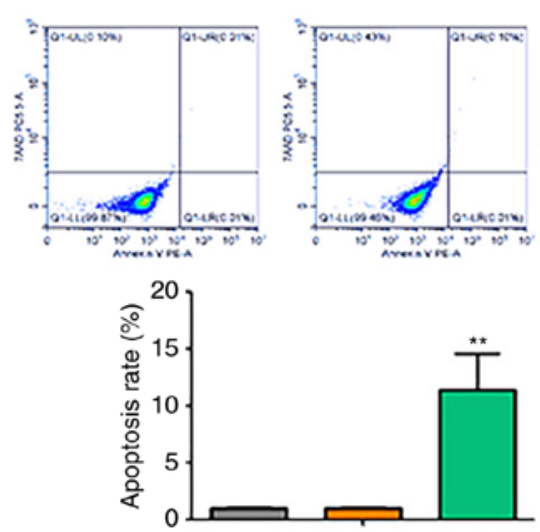

C

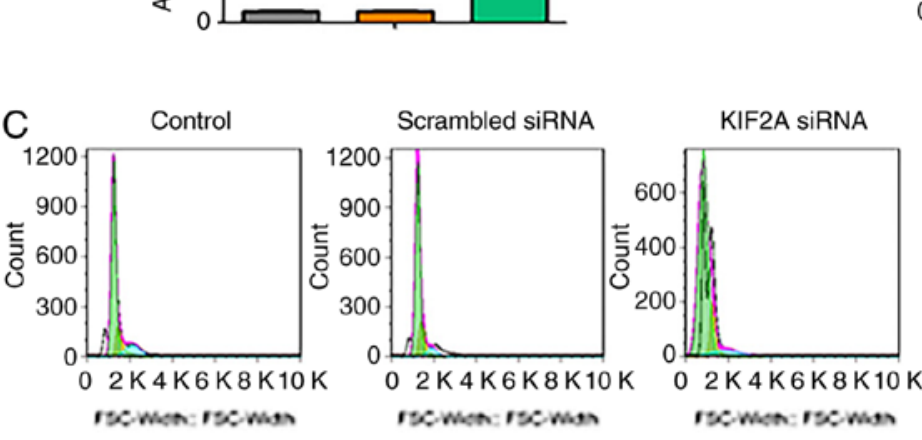

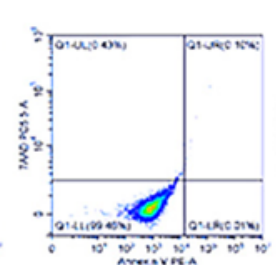

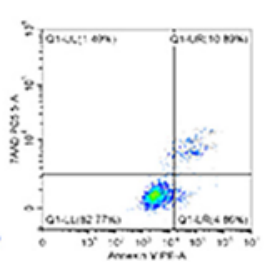

B

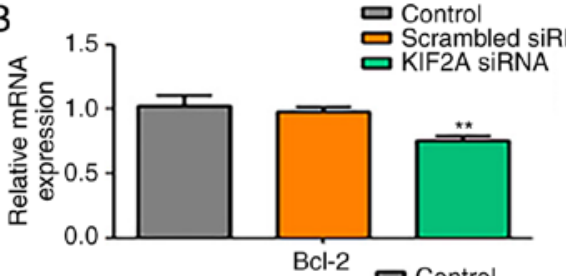

Control $\square$ Scrambled siRNA GIF2A SiRNA
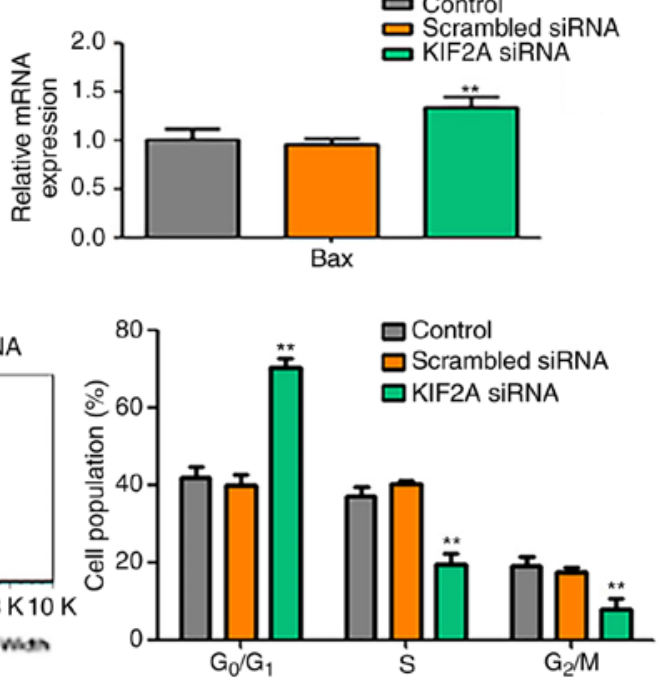

Figure 2. Effects of KIF2A knockdown on the apoptosis and cell cycle of 5-8F cells. (A) Apoptotic cells were detected by flow cytometry. (B) Bcl-2 and Bax expression levels were detected by reverse transcription-quantitative PCR. (C) The cell cycle was investigated by flow cytometry. ${ }^{* *} \mathrm{P}<0.01$ vs. mock treatment control. KIF2A, kinesin family member $2 \mathrm{a}$; siRNA, small interfering RNA.

\section{Discussion}

Nasopharyngeal carcinoma (NPC), a common malignant tumor, derives from the nasopharyngeal epithelium (20-22).
The long-term survival rate for NPC patients is currently unsatisfactory. Therefore, it is important to investigate the molecular mechanisms of NPC tumorigenesis and progression to improve the therapy of NPC. 

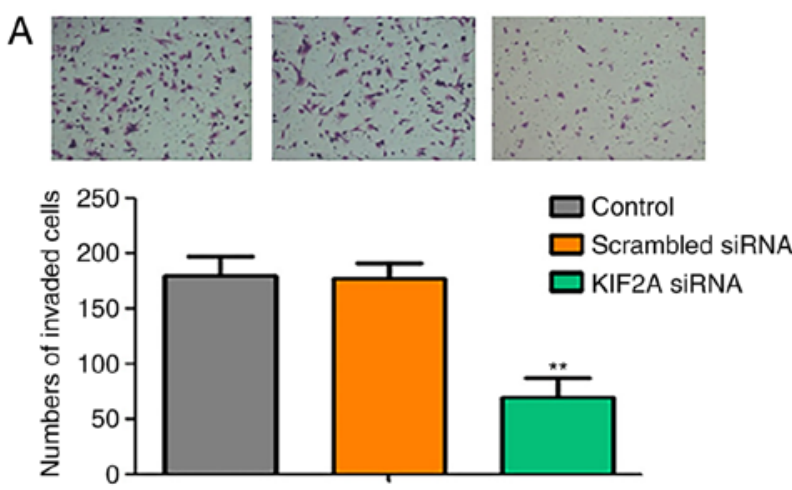

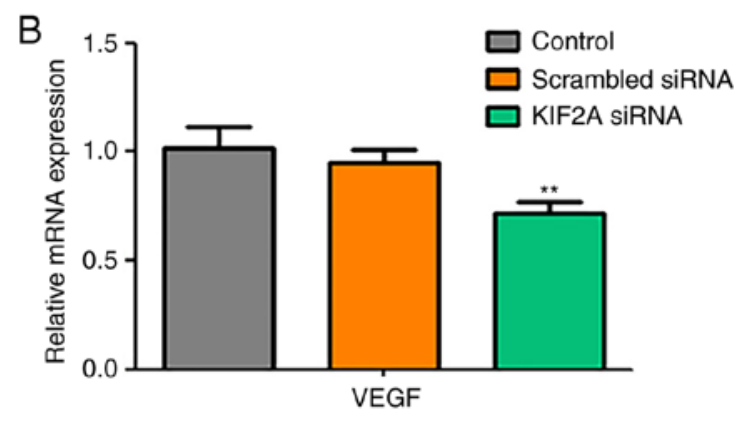

Figure 3. KIF2A inhibits the invasion and angiogenesis of 5-8F cells in the KIF2A group. (A) The invaded cells were calculated in different groups. (B) VEGF expression levels were detected by reverse transcription-quantitative PCR. Scale bar, $200 \mu \mathrm{m}$. ${ }^{* *} \mathrm{P}<0.01$ vs. mock treatment control. KIF2A, kinesin family member 2A; siRNA, small interfering RNA; VEGF, vascular endothelial growth factor.

KIF2A, which is a type of motor protein with an oncogenic function, has been identified to be overexpressed in a number of human cancers $(15,23)$. KIF2A is a member of the kinesin-13 family of proteins, and serves the function of depolymerizing the ends of microtubules (MTs) $(24,25)$. MTs are vital components of the cytoskeleton and are involved in the invasion and metastasis of cancer $(26,27)$. Therefore, the aim of the present study was to evaluate the expression of KIF2A in NPC and explore the relationship between KIF2A expression and the basic characteristics of $5-8 \mathrm{~F}$ cells.

In patients with NPC, the expression levels of KIF2A were not related with the sex and age of the patients; however, the levels of KIF2A were notably associated with the primary tumor, the nodal status and the tumor stage, which suggested that high levels of KIF2A may be associated with the malignant degree of NPC. Similarly, in a previous study, the mRNA and protein expression levels of KIF2A were significantly higher in grade III-IV glioma tissues compared with grade I-II and healthy tissues (28). Therefore, the results of the present study indicated that KIF2A may be involved in the malignant development of NPC.

A previous study demonstrated that the silencing of KIF2A significantly inhibits the growth and invasion of oral tongue squamous cell carcinoma, which suggested that KIF2A may regulate the viability and invasion of cancer cells (29). In the present study, $5-8 \mathrm{~F}$ cell proliferation decreased and apoptosis increased in the KIF2A siRNA group compared with the control groups. The $\mathrm{Bax} / \mathrm{Bcl}-2$ ratio is an effective method to identify apoptotic cells $(30,31)$. In the KIF2A siRNA group, the mRNA level of anti-apoptotic Bcl-2 decreased, whereas the pro-apoptotic Bax increased, which demonstrated that the ratio of apoptotic cells increased.

The cell cycle analysis in the present study demonstrated that the number of cells arrested at the G0/G1 phase was increased in the KIF2A siRNA group compared with the control groups. A recent study has revealed that the MRE11-RAD50-NBS1 complex activates KIF2A, which leads to spindle turnover and DNA damage (11); therefore, KIF2A may be associated with the DNA structure and spindle dynamics.

In addition, the results of the present study demonstrated that the invasive ability and the expression of the angiogenesis marker VEGF in 5-8F cells were inhibited in the KIF2A siRNA group compared with the control groups. A previous study has reported that KIF2A is associated with the prognosis of ovarian cancer, and the inhibition of KIF2A decreases invasion in ovarian cancer in vitro (15). Downregulation of KIF2A inhibits gastric cancer cell invasion by suppressing membrane type I-matrix metallopeptidase (32). Therefore, KIF2A may be associated with the invasion and angiogenesis of $5-8 \mathrm{~F}$ cells.

In conclusion, the present study demonstrated that the expression of KIF2A was correlated with poor clinicopathological features in NPC. In addition, KIF2A may serve an important role in the progression of NPC and the proliferation $5-8 \mathrm{~F}$ cells.

\section{Acknowledgements}

Not applicable.

\section{Funding}

The present study was supported by the Qingyuan Science and Technology Project (grant no. 2016B030).

\section{Availability of data and materials}

The datasets used and/or analyzed during the current study are available from the corresponding author upon reasonable request.

\section{Authors' contributions}

CC and QZ designed the study. QZ, TL and CC guided the experiments. QZ, DL and WL performed the experiments. QZ, SY and HG collected and processed the clinical data. QZ, HG and TL analyzed and interpreted the patient data. QZ wrote the paper, and TL and CC reviewed and edited the manuscript. All authors read and approved the final manuscript.

\section{Ethics approval and consent to participate}

Sample collection protocols were approved by the Ethics Committee of the Sixth Affiliated Hospital of Guangzhou Medical University (approval no. ERC-2016-33). Written informed consent was obtained from all patients. 


\section{Patient consent for publication}

Not applicable.

\section{Competing interests}

The authors declare that they have no competing interests.

\section{References}

1. Wei KR, Zheng RS, Zhang SW, Liang ZH, Li ZM and Chen WQ: Nasopharyngeal carcinoma incidence and mortality in China, 2013. Chin J Cancer 36: 90, 2017.

2. Tang XR, Li YQ, Liang SB, Jiang W, Liu F, Ge WX, Tang LL, Mao YP, He QM, Yang XJ, et al: Development and validation of a gene expression-based signature to predict distant metastasis in locoregionally advanced nasopharyngeal carcinoma: A retrospective, multicentre, cohort study. Lancet Oncol 19: 382-393, 2018.

3. Zhang F, Li J, Xiao H, Zou Y, Liu Y and Huang W: AFAP1-AS1: A novel oncogenic long non-coding RNA in human cancers. Cell Prolif 51, 2018

4. Tsao SW, Tsang CM and Lo KW: Epstein-Barr virus infection and nasopharyngeal carcinoma. Philos Trans R Soc Lond B Biol Sci 19: 372, 2017.

5. He JY, Han P, Zhang Y, Liu YD, Song SJ, Feng GK, An Y, Zhou AJ, Wang HB, Yuan L, et al: Overexpression of Nogo receptor 3 (NgR3) correlates with poor prognosis and contributes to the migration of epithelial cells of nasopharyngeal carcinoma patients. J Mol Med (Berl) 96: 265-279, 2018.

6. Zhu JF, Huang W, Yi HM, Xiao T, Li JY, Feng J, Yi H, Lu SS $\mathrm{Li} \mathrm{XH}, \mathrm{Lu} \mathrm{RH}$, et al: Annexin A1-suppressed autophagy promotes nasopharyngeal carcinoma cell invasion and metastasis by PI3K/AKT signaling activation. Cell Death Dis 9: 1154, 2018.

7. You R, Cao YS, Huang PY, Chen L, Yang Q, Liu YP, Zou X, Zhang YN, Jiang R, Zhang MX, et al: The changing therapeutic role of chemo-radiotherapy for loco-regionally advanced nasopharyngeal carcinoma from two/three-dimensional radiotherapy to intensity-modulated radiotherapy: A network meta-analysis. Theranostics 7: 4825-4835, 2017

8. Xie P, Yang JP, Cao Y, Peng LX, Zheng LS, Sun R, Meng DF, Wang MY, Mei Y, Qiang YY, et al: Promoting tumorigenesis in nasopharyngeal carcinoma, NEDD8 serves as a potential theranostic target. Cell Death Dis 8: e2834, 2017.

9. Lucanus AJ and Yip GW: Kinesin superfamily: Roles in breast cancer, patient prognosis and therapeutics. Oncogene 37: 833-838, 2018

10. Chen J, Li S, Zhou S, Cao S, Lou Y, Shen H, Yin J and Li G: Kinesin superfamily protein expression and its association with progression and prognosis in hepatocellular carcinoma. J Cancer Res Ther 13: 651-659, 2017.

11. Xu R, Xu Y, Huo W, Lv Z, Yuan J, Ning S, Wang Q, Hou M, Gao G, $\mathrm{Ji}$ J, et al: Mitosis-specific MRN complex promotes a mitotic signaling cascade to regulate spindle dynamics and chromosome segregation. Proc Natl Acad Sci USA 115: E10079-E10088, 2018.

12. Chen MH, Liu Y, Wang YL, Liu R, Xu BH, Zhang F, Li FP, Xu L, Lin $\mathrm{YH}, \mathrm{He} \mathrm{SW}$, et al: KIF2A regulates the spindle assembly and the metaphase I-anaphase I transition in mouse oocyte. Sci Rep 6: 39337, 2016.

13. Tao T, Chen M, Jiang R, Guan H, Huang Y, Su H, Hu Q, Han X and Xiao J: Involvement of EZH2 in aerobic glycolysis of prostate cancer through miR-181b/HK2 axis. Oncol Rep 37: 1430-1436, 2017.

14. Zhao P, Lan F, Zhang H, Zeng G and Liu D: Down-regulation of KIF2A inhibits gastric cancer cell invasion via suppressing MT1-MMP. Clin Exp Pharmacol Physiol 45: 1010-1018, 2018.

15. Sheng N, Xu YZ, Xi QH, Jiang HY, Wang CY, Zhang Y and Ye Q: Overexpression of KIF2A is suppressed by miR-206 and associated with poor prognosis in ovarian cancer. Cell Physiol Biochem 50: 810-822, 2018.
16. Palazzi M, Guzzo M, Tomatis S, Cerrotta A, Potepan P, Quattrone $\mathrm{P}$ and Cantù G: Improved outcome of nasopharyngeal carcinoma treated with conventional radiotherapy. Int J Radiat Oncol Biol Phys 60: 1451-1458, 2004.

17. OuYang PY, You KY, Zhang LN, Xiao Y, Zhang XM and Xie FY: External validity of a prognostic nomogram for locoregionally advanced nasopharyngeal carcinoma based on the 8th edition of the AJCC/UICC staging system: A retrospective cohort study. Cancer Commun (Lond) 38: 55, 2018.

18. Anufrieva KS, Shender VC, Arapidi GP, Pavlyukov MS, Shakhparonov MI, Shnaider PV, Butenko IO, Lagarkova MA and Govorun VM: Therapy-induced stress response is associated with downregulation of pre-mRNA splicing in cancer cells. Genome Med 10: 49, 2018.

19. Livak KJ and Schmittgen TD: Analysis of relative gene expression data using real-time quantitative PCR and the 2(-Delta Delta $\mathrm{C}(\mathrm{T})$ ) method. Methods 25: 402-408, 2001

20. Xing H, Chen X and Han Y: Role of regenerating gene IA expression on local invasion and survival in nasopharyngeal carcinoma. Biol Res 50: 37, 2017.

21. Zuo LL, Zhang J, Liu LZ, Zhou Q, Du SJ, Xin SY, Ning ZP, Yang J, Yu HB, Yue WX, et al: Cadherin 6 is activated by Epstein-Barr virus LMP1 to mediate EMT and metastasis as an interplay node of multiple pathways in nasopharyngeal carcinoma. Oncogenesis 6: 402, 2017.

22. Xing H, Chen X and Han Y: Role of regenerating gene IA expression on local invasion and survival in nasopharyngeal carcinoma. Biol Res 50: 37, 2017.

23. Watanabe T, Kakeno M, Matsui T, Sugiyama I, Arimura N, Matsuzawa K, Shirahige A, Ishidate F, Nishioka T, Taya S, et al: TTBK2 with EB1/3 regulates microtubule dynamics in migrating cells through KIF2A phosphorylation. J Cell Biol 210: 737-751, 2015.

24. Ali A, Veeranki SN, Chinchole A and Tyagi S: MLL/WDR5 complex regulates Kif2A localization to ensure chromosome congression and proper spindle assembly during mitosis. Dev Cell 41: 605-622, 2017.

25. Kwon HJ, Park JE, Song H and Jang CY: DDA3 and Mdp3 modulate Kif2a recruitment onto the mitotic spindle to control minus-end spindle dynamics. J Cell Sci 129: 2719-2725, 2016.

26. Yan C, Wang F, Peng Y, Williams CR, Jenkins B, Wildonger J, Kim HJ, Perr JB, Vaughan JC, Kern ME, et al: Microtubule acetylation is required for mechanosensation in drosophila. Cell Rep 25: 1051-1065.e6, 2018.

27. Sandi MJ,Marshall CB,Balan M,Coyaud É,Zhou M,Monson DM, Ishiyama N, Chandrakumar AA, La Rose J, Couzens AL, et al: MARK3-mediated phosphorylation of ARHGEF2 couples microtubules to the actin cytoskeleton to establish cell polarity. Sci Signal 10: pii: eaan3286, 2017.

28. Zhang X, Ma C, Wang Q, Liu J, Tian M, Yuan Y, Li X and Qu X: Role of KIF2A in the progression and metastasis of human glioma. Mol Med Rep 13: 1781-1787, 2016.

29. Wang CQ, Li YJ, Wei ZM, Zhu CJ, Qu X, Wei FC, Xing XM and $\mathrm{Yu}$ WJ: Stable gene-silence of Kif2a synergistic with 5-fluorouracil suppresses oral tongue squamous cell carcinoma growth in vitro and in vivo. Oral Surg Oral Med Oral Pathol Oral Radiol 116: 49-54, 2013.

30. Zhang P, Zhang Y, Liu K, Liu B, Xu W, Gao J, Ding L and Tao L: Ivermectin induces cell cycle arrest and apoptosis of HeLa cells via mitochondrial pathway. Cell Prolif 52: e12543, 2019.

31. Zhou S, Wang Y and Zhu JJ: Simultaneous detection of tumor cell apoptosis regulators $\mathrm{Bcl}-2$ and bax through a dual-signal-marked electrochemical immunosensor. ACS Appl Mater Interfaces 8: 7674-7682, 2016.

32. Zhao P, Lan F, Zhang H, Zeng G and Liu D: Down-regulation of KIF2A inhibits gastric cancer cell invasion via suppressing MT1-MMP. Clin Exp Pharmacol Physiol 45: 1010-1018, 2018. 